\title{
Research on the Current Situation and Reform of Experimental Teaching of Exercise Physiology in Colleges \\ Zimin Chang
}

NanChang Institute of Science and Technology, Nanchang, 330108

Keywords: College; Exercise physiology teaching; Current situation; Reform

\begin{abstract}
Exercise skills and basic theory are the necessary professional foundation for college students majoring in physical education. The mastery of exercise skills and the study of theoretical knowledge are complementary processes. The basic theories originate from the practice of exercise, and the exercise of practice deepens the theoretical knowledge. "Exercise Physiology" is the compulsory basic theory course of PE major in colleges. The curriculum reform of colleges makes great changes in the proportion of this course during the course of study, and the duration of study decreases a lot when compared with that before the reform. How to ensure the integrity and systematicness of teaching contents within a limited number of teaching hours, so to adopt an effective teaching mode is an important issue that teachers should think about. This article aims at the teaching reform of sports physiology in colleges
\end{abstract}

\section{Introduction}

In recent years, due to the vigorous development of higher education in our country, the major of physical education is no longer confined to single-sport sports colleges and normal colleges. More and more normal colleges and general colleges even some colleges of science and engineering set the sports professional. This undoubtedly played a huge role in promoting high-level sports talents. However, on the other hand, many colleges are not able to guarantee the quality of professional teaching and personnel training due to the weak foundation of their schooling and lack of experience, and the continuous expansion of enrollment. Especially as an important part of cultivating students' practice and innovation ability, there are still some problems in the construction and experiment teaching of PE specialty laboratory. There is a big gap compared with PE major in single subject, which can not meet the requirements of the new century high-quality innovative personnel training needs. Therefore, this article from the sports physiology experimental teaching for research, deepening the experimental teaching reform, in order to strengthen students' comprehensive practice ability training.

\section{Streamlining of Exercise Teaching Content}

The basic contents of Exercise Physiology include basic physiology and applied physiology. For sports majors, based on different academic backgrounds, there is a difference in the degree of perceived difficulty in the course of "Exercise Physiology". It is not an easy task to understand this comprehensive curriculum based on biology, physiology, sports training, and anatomy. In a limited time, you need to focus on teaching content, difficult to fully grasp it. Combined with the teaching content of other disciplines, we remove the contents of this course that other disciplines have already mentioned and require students to review or master the extra-curricular time. Such as skeletal muscle fiber structure part of the contents of the anatomy of the movement; circulatory system of heart function and vascular physiology part of the basic structure of the kidneys and sensory organs in the anatomy of the movement has been studied.

Within a limited number of teaching hours, the effective selection of teaching contents, difficulties and priorities, general clear-cut mastery, and reasonable selection of the key teaching contents in other disciplines is the basic guarantee to make it possible to conduct systematic, comprehensive and effective teaching of "exercise physiology". Seeking the whole is not allowed under realistic conditions, refinement is the first principle. Based on the combination of students' 
major, we focus on the teaching of knowledge related to sports practice and apply what we have learned. "Eyebrows beard scratching together" is bound to take care of each other, which can not get good results in the teaching process. Only by doing so can the primary and secondary points be separated to ensure the systematic, complete and efficient teaching of "exercise physiology" in the current situation.

\section{Current Situation of Experimental Teaching of Exercise Physiology in Colleges}

For ordinary PE major in higher education, the Ministry of Education has formulated strict teaching requirements, requiring six scientific experiments on human exercise, including: Exercise biomechanics, Exercise Health Science, Exercise Physiology, Exercise Anatomy Learning, Sports Biochemistry, Physical Education. The establishment of these six disciplines should be indispensable. However, in the actual investigation, we found that a small number of colleges lacked the laboratories of "sports physiology" due to lack of funds or lack of leadership, which led teachers can not normally carry out physical education in the actual class. The establishment of a sports physiology laboratory colleges, and most can not meet the country's requirements for laboratory size and quality, most of the college laboratories are relatively small, the conditions are very simple, even the basic laboratory standard does not have. As the low-quality laboratory standards directly affect the physical performance of some sports test, resulting in the school's physical education teaching quality can not be improved.

At the same time, there are also some deficiencies in the management of the laboratory. During the investigation, we found that some colleges did not have any shortage of professional laboratory managers or managers. Therefore, when there is a problem in the laboratory equipment, which can not get timely repair and treatment, the normal maintenance work is also very poor, and even some experimental teaching in colleges by part-time theoretical teachers. As a result of these problems, the quality of physiology experiment teaching in ordinary universities can not be improved nowadays. At the same time, the professional issues of laboratory technicians also need to be valued.

\section{Research on Related Reform of Experimental Teaching of Exercise Physiology in Colleges}

Transformation of Experimental Teaching Concept. There are a lot of ordinary colleges have a serious lack of understanding of the sports profession, often focusing on sports technology but ignoring the theory and experiment, from now on, we should slowly change this teaching philosophy. Nowadays, more and more people begin to focus on quality education, and experimental teaching plays an important role in cultivating students' innovative ability, practical ability and comprehensive analytical ability. Therefore, the leader of the schools need to strengthen the experimental curriculum in the entire school.

Optimize the Experimental Teaching Team. High-quality teaching team for the entire school's teaching level has an important impact, therefore, schools should strengthen the ability to inspect the teaching staff to strengthen the quality of the teaching staff. Considering teachers' educational level, age structure and other aspects, we should formulate a teaching direction that adapts to experimental teaching and clarify the main responsibilities of teachers. Teachers should not only master the relevant knowledge of sports physiology, but also keep up with the development trend of the times, to advance with the times. Colleges should regularly carry out training of teachers, and constantly expand their knowledge of grain reserves and practical ability, and strengthen the optimization of the teaching staff.

Achieve Diversification of Teaching Methods. With the progress of the times, more and more teaching contents need to be presented by means of multimedia technology. When teachers explain some verifiable contents, they can use multimedia to play video. This will allow students to more fully understand each step, but also to a certain extent, saving teaching costs. Interactive teaching, in the teaching process, teachers can be based on some of the characteristics of students in the group distribution, require students to conduct group experiments, to explore and learn independently. 
This can effectively develop students' self-learning ability and enhance their sense of innovation. In addition, in the teaching process, we should pay attention to observe the performance of students, take the initiative to communicate with students on the problems in teaching, respect for students' effective advice, improve the degree of integration in the classroom, timely improve inadequate teaching methods, so that allow students to more actively involved in learning.

\section{Conclusion}

Attention paid to sports professionals, to a large extent, promotes the cultivation of sports professionals in China's higher education and training, absolutely beneficial. However, at the same time, because many of the schools themselves have little experience in running schools and the foundation is not strong, and the enrollment scale of many colleges in our country is increasing year by year, it is difficult to raise the quality of teaching and the cultivation of qualified personnel while guaranteeing the quantity. Therefore, only if we can get a more comprehensive and detailed understanding of the status quo of experimental teaching of physical exercise of ordinary colleges in our country, deepening the reform of experimental teaching to strengthen the students' comprehensive quality and practical ability, which is what modern PE teachers should solve important content.

\section{References}

[1] Opondo M A, Sarma S, Levine B D. The Cardiovascular Physiology of Sports and Exercise [J] Clinics in Sports Medicine, 2015, 34(3):391-404

[2] freemover@oru.se. Sports Physiology and Medicine Programme, 120 credits, ht 2014 - Örebro university $[\mathrm{J}]$.

[3] Yan X, Fang Y,Cao C. Empirical Analysis on the Characteristic Model of Girls' Sports Teaching Based on the Element Characteristics of Physiology and Psychology [J]. Studies in Preschool Education, 2013, 2004: 91-92

[4] You X F, Review on the Influence of National Traditional Sports on Physiology and Biochemistry[J]. Bulletin of Sport Science \& Technology, 2011.

[5] Neptune R R, Mcgowan C P, Fiandt J M. The influence of muscle physiology and advanced technology on sports performance[J] Annual Review of Biomedical Engineering, 2009, 11(4):81-107

[6] Kelc R, Naranda J, Kuhta M, et al. The Physiology of Sports Injuries and Repair Processes[M]// Current Issues in Sports and Exercise Medicine. 2013:43-86

[7] Li T. On the Present Situation and Reform of Experiment Teaching of PE Major's Sports Physiology at Jishou University [J] Wushu Science, 2015

[8] Pyne D. Sports physiology research-moving to shorter and faster publication [J] International Journal of Sports Physiology \& Performance, 2013, 8(2):109.

[9] Hong-Ying L I. Analysis of Physiology about Health Education and Sports Teaching [J] Journal of Tongren Vocational \& Technical College, 2012.

[10]Wang X X. Reform and exploration of Professional Athletes Sports Physiology Course [J] Journal of Sichuan College of Education, 2010

[11]The Proceedings of the 22nd Annual Meetings of Japan Society of Exercise and Sports Physiology July 19,20 (Okayama)[J] Advances in Exercise \& Sports Physiology, 2014, 20:67, $75-122$

[12]Håkan Larsson. Sport physiology research and governing gender in sport-a power-knowledge relation[J] Sport Education \& Society, 2013, 18(3):334-348 